\title{
Het leren en toetsen van de professionele rol
}

\author{
S.J. van Luijk, W.N.K.A. van Mook, W.P.J. van Oosterhout
}

\begin{abstract}
Samenvatting
Inleiding: Er bestaat onduidelijkheid in de medische onderwijskundige wereld over het begrip 'professionaliteit'. Deze onduidelijkheid vertaalt zich ook in wat geleerd en getoetst moet worden. De omschrijving die de CanMEDS (Canadian Medical Education Directions for Specialists) geeft wordt als te beperkt gezien. In dit artikel wordt getracht het begrip professionaliteit te definiëren vanuit de taken die een (medische) professional vervult binnen de samenleving met hieraan gekoppeld de consequenties voor het onderwijs en toetsing.

Methode: Door middel van een literatuurstudie is onderzoek verricht naar de opvattingen over de rol en betekenis van de professie en de professional.

Resultaten: Uit de literatuur blijkt dat de betekenis van de professionaliteit in de kern dezelfde is voor alle beroepsgroepen maar afhankelijk is van context, cultuur en het tijdsgewricht. Dit verklaart waarom er zoveel spraakverwarring rondom het begrip professionaliteit bestaat. Het is dan ook een dynamisch begrip! Het vastleggen van een definitie met betrekking tot het begrip professionaliteit kan dus niet anders dan globaal en is gebonden aan een bepaalde tijd en context. Uit de studie blijkt eveneens dat het geheel aan professionele taken deel uitmaakt van alle competenties die door de CanMEDS worden beschreven. Derhalve wordt gepleit voor een alternatief CanMEDS model waarbij het begrip professionaliteit alle overige CanMEDS competenties omvat.

In dit artikel worden verschillende beroepsrollen van de professional genoemd. Hierbij worden onderscheiden: de professional als individuele zorgverlener, de professional als lid van een (behandel)team, de professional binnen de context van de organisatie en de professional binnen de context van de maatschappij. Elke rol heeft specifieke kenmerken die een beroep doen op specifieke aspecten van professionaliteit. Dit betekent ook dat het leren en toetsen van professionele vaardigheden afhankelijk hoort te zijn van de rol(len) die de professional bekleedt. Dit artikel biedt aan de hand van concrete situaties op de werkvloer inzicht in de vele mogelijkheden die er zijn voor het bespreken van aspecten van professionaliteit.

Conclusie: Professionaliteit kan gezien worden als een competentie die alle andere competenties omvat. Deze opvatting wordt reeds langer door de (medische) beroepsgroep bepleit. Alles wat onderwezen en getoetst wordt valt onder dit begrip, waarbij het aspect van de professionaliteit dat benadrukt wordt wel afhankelijk is van de rol die de professional vervult. Belangrijk is dat professionaliteit in een voor het beroep realistische context wordt onderwezen en getoetst. (Luijk SJ van, Mook WNKA van, Oosterhout, WPJ van. Het leren en toetsen van professionaliteit. Tijdschrift voor Medisch Onderwijs 2009;28(3):107-118.)
\end{abstract}

Inleiding

Binnen de medische beroepsgroep is professionaliteit een veel gebruikte term. Hoe bekend deze term echter ook is, de meningen verschillen over de betekenis ervan. ${ }^{1-2}$ Dit wordt veroorzaakt door de 
onduidelijke definiëring van het begrip. Om hier meer inzicht in te krijgen is een literatuurstudie verricht naar de rol en betekenis van de professie en de professional. Een duidelijker beeld over de professie en de rol van de professional kan meer inzicht verschaffen in het gedrag van professionals binnen diverse contexten. Hieruit kan een nadere beschrijving van het begrip professionaliteit worden afgeleid. Vervolgens komen de consequenties voor het onderwijs en implicaties voor de praktijk en vervolgonderzoek aan bod.

\section{Methode}

Er is een literatuursearch verricht met de trefwoorden 'profession' en 'professional' in Picarta en PubMed. In beide databases zijn de artikelen van de afgelopen vijf jaar tot mei 2008 met deze trefwoorden opgezocht en is aan de hand van de titel beoordeeld of het hier artikelen betrof die inzicht zouden kunnen geven in de genese en betekenis van de begrippen 'profession' en 'professional'. Tevens is in beide databases gezocht naar artikelen gericht op 'assessment' (title) en 'professionals' (focus). Geïncludeerd zijn ook die Engelstalige of Nederlandstalige artikelen die informatie konden verschaffen over de genese en betekenis van het begrip professionaliteit en informatief waren ten aanzien van het onderwijs en de toetsing ervan.

In totaal zijn 45 artikelen geselecteerd waarvan er uiteindelijk 20 bruikbaar bleken. Additioneel zijn relevante referenties toegevoegd die niet in deze databases voorkwamen. Zo zijn artikelen uit Medisch Contact opgenomen waarin actuele ontwikkelingen in de gezondheidszorg met consequenties voor de professionele rol van artsen beschreven werden.

\section{Resultaten}

\section{Definiëring professie}

Het woord professie komt van oorsprong uit het Latijn ('profiteri') en werd gebruikt in een religieuze en wetenschappelijke context in de betekenis van 'openbaar verklaren'. Een professie ${ }^{3-9}$ is een organisatie van dezelfde beroepsbeoefenaren waarbij de leden beschikken over gespecialiseerde kennis en vaardigheden die zijn opgedaan door uitgebreide studie in een door de professie zelf verzorgde opleiding. Elke professie kent een zekere autonomie binnen de maatschappij die haar gegund wordt als tegenprestatie voor het leveren van de eerder genoemde kennis en vaardigheden aan de overige leden van de maatschappij (sociaal contract). De maatschappij stelt de professie in staat haar eigen regels ten aanzien van kwaliteit op te stellen. Ditzelfde geldt voor het opstellen van de ethische (beroeps)code en regelgeving als die code wordt geschonden (tucht). In de afgelopen jaren is een trend zichtbaar waarbij de maatschappij in toenemende mate verwacht dat de beroepsgroep verantwoording aflegt over al haar activiteiten op een wijze die recht doet aan de door haar opgestelde regels, inclusief het ethisch kader. ${ }^{10}$

\section{Veranderende rol professional}

De laatste 25 jaar zijn er belangrijke veranderingen waarneembaar in de rol van de professional, die vaak niet uniek zijn voor de geneeskunde maar ook andere professies betreft. De meest opvallende punten komen achtereenvolgens aan de orde. Kenmerkend voor onderstaande veranderingen is dat ze alle te maken hebben met een verlies aan autonomie en met een toenemende verantwoordingsplicht. In dat verband wordt wel gesproken van een 'proletarisering' van de professional. ${ }^{11}$ 


\section{Van individuele (kennis)expert naar} onderhandelaar met (expert)patiënt

Professionals beschikken weliswaar over kennis en vaardigheden als gevolg van langdurige training, maar patiënten kunnen tegenwoordig via internet ook aan de benodigde informatie komen en daardoor de arts benaderen met kritische vragen over diagnose, beleid en therapie. Het medisch kennisdomein is dus deels 'gedemocratiseerd', hoewel de arts uiteindelijk de informatie het beste op waarde kan wegen en beoordelen. ${ }^{12}$

\section{Van solist naar teamplayer}

De solistische arts van vroeger die volledige handelingsvrijheid had bestaat al lang niet meer. Hedendaagse artsen moeten in teams werken om optimale zorg te kunnen verlenen. Teamwerk betekent onderling afspraken maken en leidt derhalve tot een beperking van de autonomie in vergelijking tot de solistische arts van vroeger. ${ }^{13-14}$

\section{Van zelfstandige naar professional binnen de organisatie}

De instelling waarbij een arts werkt (bijvoorbeeld ziekenhuis) reguleert processen en stelt op verschillende niveaus procedures vast die het werk van artsen kunnen beïnvloeden. Dit is zeker het geval op die plaatsen waar management een prominente rol heeft binnen het zorgproces. Dit beperkt de autonome rol van de arts in het zorgproces.

\section{Van interne naar externe verantwoor-} ding van kwaliteit van zorg

De kwaliteit van de zorg werd in het verleden exclusief door de professie bewaakt. Daartoe werden ethische codes geformuleerd en later richtlijnen voor optimale behandeling. Tegenwoordig worden beroepsgroepen regelmatig door vakgenoten gevisiteerd. Hierbij wordt niet alleen op de inhoudelijke 'evidence based' kwaliteit van zorg gelet, maar ook op de organisatie van de zorg, de patiëntveiligheid en de kwaliteit van de opleiding. Toch is het systeem van kwaliteitszorg aan erosie onderhevig. Door het falen van de door de beroepsgroep opgezette kwaliteitszorg in binnen- en buitenland ${ }^{15-17}$ is het handelen van artsen veel meer publiek domein geworden en wordt de roep om een externe verantwoording naast een interne regulering van medisch handelen steeds duidelijker. Het formuleren van kwaliteitsindicatoren voor de zorg is hier een voorbeeld van. ${ }^{18-20}$

\section{Van incidentele bijscholing naar} continue professionele ontwikkeling In het verleden bestond weinig aandacht voor structurele professionele ontwikkeling na het afstuderen. De beroepsgroep heeft inmiddels bepaald dat een continue nascholing belangrijk is voor het bijhouden van het vakgebied. Artsen dienen voor het behoud van hun registratie minimaal een bepaald aantal nascholingspunten per jaar te behalen.

\section{Van hulpverlener aan patiënt naar hulpverlener aan consument}

De patiëntenpopulatie is de afgelopen 25 jaar sterk veranderd. De patiënt is niet alleen beter op de hoogte van verschijnselen en gevolgen van ziekten door raadpleging van internet, maar ook door de toename van medische programma's op televisie, en is kritisch ten aanzien van de geleverde zorg. Meer dan vroeger wil de patiënt inspraak in het zorg- en behandelplan, hetgeen ook door wettelijke maatregelen wordt ondersteund. ${ }^{21-22}$

\section{Van 'experience based' naar 'evidence based' handelen}

Ervaring blijft belangrijk, maar het medisch handelen van de huidige profes- 
sional wordt in toenemende mate bepaald door 'evidence' met betrekking tot het ingezette beleid en therapie. ${ }^{23}$

\section{Het functioneren van de professional in verschillende contexten}

Het bovenstaande toont aan dat de arts een zeer veelzijdig pakket aan taken heeft die alle samenkomen in de CanMEDS competenties (Figuur 1).

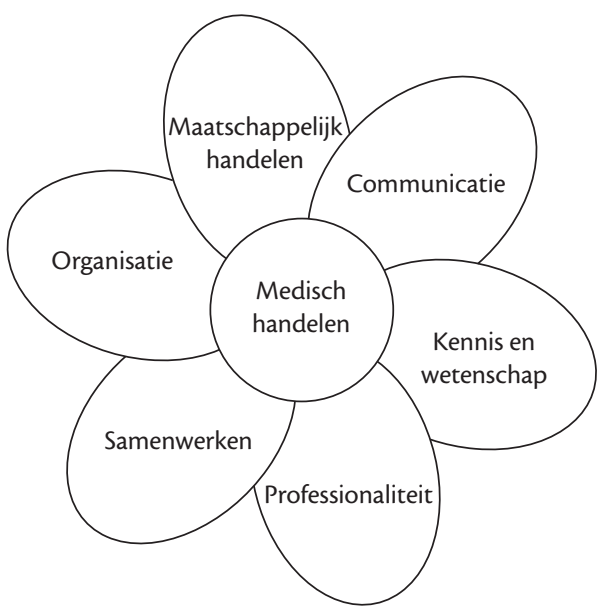

Figuur 1. CanMEDS zoals oorspronkelijk gedefinieerd.

Afhankelijk van de context komen bepaalde gedragsaspecten van de professional naar voren. De verschillende rollen waarin de medische professional functioneert zijn als volgt te beschrijven.

\section{De arts in de rol van professional als individuele hulpverlener}

Binnen de professionele arts-patiëntrelatie wordt met name een beroep gedaan op de CanMEDS competentie 'medisch handelen' op basis van evidentie en op de competenties 'kennis en wetenschap' en 'professionaliteit'. Hierbij wordt professionaliteit geoperationaliseerd als respectvol en integer handelen, communiceren, organiseren op individueel niveau en reflecteren.
De arts in de rol van professional als lid van een team belast met patiëntenzorg

Solitair werkende artsen zullen in de toekomst verdwijnen. Teams van gezondheidszorgwerkers waar artsen deel van uitmaken zullen het toekomstbeeld bepalen en de kwaliteit van de geleverde zorg door de professional wordt mede bepaald door het vermogen in deze teams te werken. Eveneens is men verantwoording aan derden schuldig over het handelen. Binnen deze context komen met name aspecten naar voren als medisch handelen, samenwerken, management en, op een ander niveau dan in de vorige rol, de competenties 'organiseren' en 'communiceren'.

\section{De arts in de rol van professional als onderdeel van een organisatie}

De arts kan zich in de beroepsuitoefening niet onttrekken aan de regels van de organisatie (bijvoorbeeld een ziekenhuis) waarbinnen gewerkt wordt en evenmin aan de regels die opgelegd zijn door de beroepsorganisatie waartoe de arts behoort. Het (normatieve) gedrag van een professional wordt beïnvloed door de organisatie en het sociale netwerk waarin de professional zich bevindt. ${ }^{24-25}$ Een beroepsbeoefenaar met een summier netwerk binnen de organisatie loopt grote kans zich minder snel aan te passen aan veranderende normen en waarden binnen die organisatie. Organisaties zullen het gedrag van de professional sturen via protocollen en richtlijnen die niet alleen behulpzaam kunnen zijn wanneer men te maken heeft met bijvoorbeeld patiëntveiligheid maar ook bij contrasterende belangen, regels en mores waarbij keuzes gemaakt moeten worden. Wanneer de professional zich een positie in de organisatie wil verwerven zullen naast de eigenschappen genoemd in de voorgaande rollen ook leiderschap, managementkwaliteiten, organiseren en communiceren (alle even- 
eens op een ander niveau dan in de vorige rol) tot expressie moeten komen.

\section{De arts in de rol van professional binnen de maatschappij}

De rol van de professional strekt zich uit tot buiten de spreekkamer of de organisatie waarbinnen gewerkt wordt. Professionals hebben een professionele verantwoordelijkheid naar de maatschappij voor zover deze betrekking heeft op het bevorderen van de individuele en collectieve gezondheidszorg. Naast deze maatschappelijke rol wordt ook gevraagd financiële verantwoording af te leggen over de kosten van kerntaken ${ }^{26}$ van de professional omdat er altijd sprake is van een 'krapte'-model waarbinnen de professie functioneert en er dus keuzes gemaakt moeten worden. Bovengenoemde punten vallen onder de competentie 'maatschappelijk handelen'.

Er is ook een ander raakvlak tussen professionals en maatschappij. De arts als professional handelt op basis van bepaalde normen en waarden. De normen en waarden van de professie hoeven echter niet altijd dezelfde te zijn als die van de maatschappij. Een dergelijk verschil wordt 'role morality' 27 genoemd: het claimen van een moreel recht om als professional dingen te doen die schadelijk voor anderen zijn, en soms moreel verwerpelijk, wanneer hetzelfde gedrag wordt vertoond door iemand die niet in die professionele rol zit. Hierbij kan men denken aan vragen rondom beëindiging van het leven.

Zwijgplicht en het doen of laten van bepaalde ingrepen kan ook schade toebrengen aan de (individuen binnen de) maatschappij terwijl de beroepsgroep een afgewogen oordeel kan hebben over de toepassing ervan. Het betreft gedrag van de professional in het gebied waar wrijving optreedt tussen de normen en waarden van de beroepsgroep en die van de maatschappij. Daarbij dringt zich de vraag op wie uiteindelijk bepaalt wat de grenzen zijn (van de autonomie) van de professional: de beroepsgroep of de maatschappij. Dergelijke voorbeelden zijn herkenbaar bij alle professionals. Bijvoorbeeld een rechter (professional) die een gevaarlijke crimineel vrij laat op grond van vormfouten (maatschappelijk ongewenst) of een generaal (professional) die zijn soldaten naar het front stuurt (maatschappelijk veelal ongewenst).

In Figuur 2 worden aspecten van gedrag bij elk van de professionele rollen weergegeven. Elke rol omvat het gedrag van de andere rol(len), startend vanuit het individu, via teamwerker en lid van de organisatie naar deelnemer aan de samenleving.

\section{Professionaliteit}

Hoewel de professional functioneert binnen verschillende rollen bestaat er een overlap tussen de rollen. Aspecten van de ene rol heeft men nodig voor het goed vervullen van een andere. De wijze waarop de rollen in de praktijk worden vormgegeven is een maat voor professionaliteit. Professionaliteit wordt derhalve door ons als volgt gedefinieerd:

'Het beschikken over gespecialiseerde kennis en vaardigheden opgedaan door uitgebreide training, studie en ervaring en het kunnen toepassen ervan binnen de regels opgesteld door de professie, de organisatie en de overheid, waarbij verantwoording voor het handelen wordt afgelegd aan belanghebbende partijen. Dit alles geplaatst binnen de cultuur, de context en de tijd waarbinnen dit begrip wordt gebruikt.'

Al het handelen is deel van de professionaliteit en deze opvatting is ruimer geformuleerd dan binnen de CanMEDS competenties $^{28}$ waarbij de focus ligt op integriteit, kennen van eigen grenzen, res- 
Figuur 2. Aspecten van gedrag van een professional in verschillende contexten.
Omgaan met werk / taken:

werken met richtlijnen mbt inhoudelijke aspecten en kwaliteit van zorg en patiëntveiligheid, rekenschap geven, financiële verantwoordelijkheid, bekendheid met procedures

Omgaan met anderen:

compassie met patiënten en zorgverleners

Omgaan met zichzelf:

evenwicht werk-privé, respectvol, integer, altruïstisch, kunnen reflecteren, communiceren, levenslang leren, onderschrijven ethische normen beroepsgroep,

Betrokkenheid tonen met naasten, bevorderen individuele en collectieve verantwoordelijkheid voor gezondheid streven naar het beste

\begin{tabular}{|l|l|}
\hline $\begin{array}{l}\text { Kunnen besturen, managen, risicomanagement, } \\
\text { voorzitten, onderwijs, supervisie, leiden, organiseren } \\
\text { en onderhandelen, vermijden conflicterende } \\
\text { belangen }\end{array}$ & organisatie
\end{tabular}

Box 1. CanMEDS omschrijving 'professional'.

Definition: As Professionals, physicians are committed to the health and well-being of individuals and society through ethical practice, profession-led regulation, and high personal standards of behaviour.

Description: Physicians have a unique societal role as professionals who are dedicated to the health and caring of others. Their work requires the mastery of a complex body of knowledge and skills, as well as the art of medicine. As such, the Professional Role is guided by codes of ethics and a commitment to clinical competence, the embracing of appropriate attitudes and behaviors, integrity, altruism, personal well-being, and to the promotion of the public good within their domain. These commitments form the basis of a social contract between a physician and society. Society, in return, grants physicians the privilege of profession-led regulation with the understanding that they are accountable to those served.

Key Competencies: Physicians are able to...

1. Demonstrate a commitment to their patients, profession, and society through ethical practice

2. Demonstrate a commitment to their patients, profession, and society through participation in profession-led regulation

3. Demonstrate a commitment to physician health and sustainable practice

Enabling Competencies: Physicians are able to...

1. Demonstrate a commitment to their patients, profession, and society through ethical practice

1.1 Exhibit appropriate professional behaviors in practice, including honesty, integrity, commitment, compassion, respect and altruism

1.2 Demonstrate a commitment to delivering the highest quality care and maintenance of competence

1.3. Recognize and appropriately respond to ethical issues encountered in practice

1.4. Appropriately manage conflicts of interest

1.5. Recognize the principles and limits of patient confidentiality as defined by professional practice standards and the law

1.6. Maintain appropriate relations with patients

2. Demonstrate a commitment to their patients, profession and society through participation in profession-led regulation

2.1. Appreciate the professional, legal and ethical codes of practice

2.2. Fulfill the regulatory and legal obligations required of current practice

2.3. Demonstrate accountability to professional regulatory bodies

2.4. Recognize and respond to others' unprofessional behaviours in practice

2.5. Participate in peer review

3. Demonstrate a commitment to physician health and sustainable practice

3.1. Balance personal and professional priorities to ensure personal health and a sustainable practice

3.2. Strive to heighten personal and professional awareness and insight

3.3. Recognize other professionals in need and respond appropriately 
pecteren van regels en wetten en het bezitten van de door de beroepsgroep gehanteerde ethische normen (Box 1). Dit contrasteert met onze definitie waarbij professionaliteit in feite alle CanMEDS competenties omvat (zie Figuur 3). Deze ruimere opvatting van het begrip professionaliteit sluit aan bij de opvattingen van de beroepsgroep ${ }^{29}$ en past beter bij de bestaande literatuur zowel binnen als buiten het medisch domein. Het sluit ook aan bij de wijze waarop de toetsing van professionaliteit in het competentiegerichte opleiden in de vervolgopleiding vorm heeft gekregen.

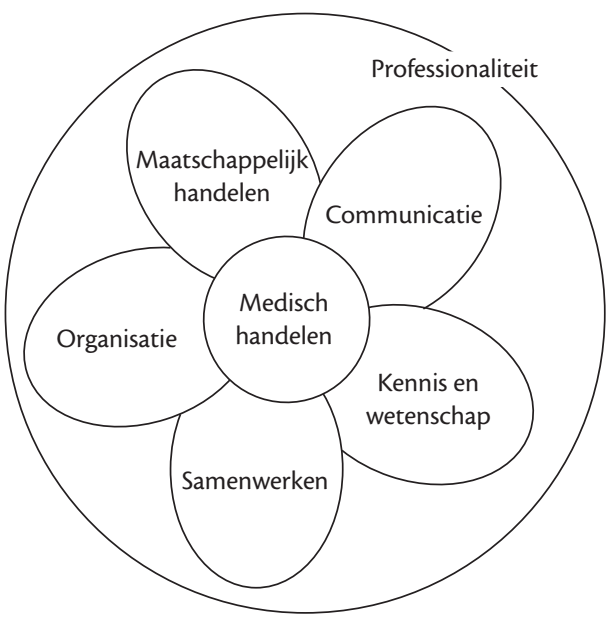

Figuur 3. CanMEDS geherdefinieerd.

Implicatie voor onderwijs en toetsing

Voor het goed kunnen functioneren als professional binnen de verschillende rollen is het belangrijk dat onderwijsmomenten en activiteiten worden gerelateerd aan deze rollen. ${ }^{30}$ Eveneens dient bepaald te worden wanneer men bekwaam is binnen een bepaalde rol. Wat betekent dit voor de onderwijspraktijk als het gaat om het leren op de werkvloer door specialisten in opleiding? Dit kan worden besproken aan de hand van Figuur 2.
De professional als individuele hulpverlener (het eerste kwadrant) beschikt over persoonskenmerken die al grotendeels gevormd zijn bij aanvang van de basisopleiding. Dat betekent dat de (vervolg) opleiding zich met name moet richten op feedback van individueel gedrag in een professionele context die wezenlijk anders is dan die van de student geneeskunde. Concreet betekent dit voor de opleiders en leden van het opleidingsteam dat artsen in opleiding tot specialist (aios) moeten worden geobserveerd binnen een authentieke context en van adequate feedback dienen te worden voorzien om daarmee de reflectie op eigen functioneren te stimuleren.

Het tweede kwadrant, de professional als teamwerker, geeft de context weer waarbij de professional geconfronteerd wordt met het samenwerken met anderen binnen de gezondheidszorg. In de basisopleiding wordt frequent (klein)groepsonderwijs gegeven maar het is de vraag of dat automatisch leidt tot de benodigde vaardigheden in teamverband. Wordt het werken in teams automatisch geleerd in het groepsonderwijs? Hier ligt een uitdaging voor de opleiding aan dit aspect meer gerichte aandacht te besteden, te beginnen in de vervolgopleiding.

Het derde kwadrant geeft de context weer, waarbij het relevant is te beschikken over organisatie- en managementvaardigheden. In feite komen deze vaardigheden in elke laag op een bepaald niveau voor alleen worden, afhankelijk van de rol, andersoortige managementstrategieën en organisatievaardigheden geëist. De organisatie van een polikliniek in de rol van individuele hulpverlener vergt andere organisatievaardigheden dan het leiden van een maatschap in een organisatie zoals het ziekenhuis. Deze vaardigheden op dit niveau heeft men in het algemeen nodig wanneer een bepaald niveau van senioriteit is bereikt. 
Het vierde kwadrant geeft aan dat de professional ook een rol heeft binnen de maatschappij. Vanuit een maatschappelijke verantwoordelijkheid dient een professional gezondheidsbevorderend gedrag na te streven door zich ondermeer te richten op preventie en screening, maar ook door zich sterk te maken voor maatschappelijke organisaties en politieke stromingen die hetzelfde doel beogen. Deze maatschappelijke rol zou binnen de opleiding meer aandacht verdienen, juist omdat de beeldvorming van de professie deels bepaald wordt door de 'wrijvingen' tussen beroepsnormen en maatschappelijke normen.

Op grond van het bovenstaande kan voor de verschillende rollen van de professional worden aangegeven welke onderwijsactiviteiten relevant zijn voor het als professional leren functioneren. In de Tabellen 1 en 2 wordt weergegeven hoe een indruk verkregen kan worden van de beheersing van die betreffende aspecten van professionaliteit. Daarbij moet worden opgemerkt dat onderwijs en toetsingsinstrumenten twee kanten van dezelfde medaille zijn. Uit beide tabellen blijkt dat er voldoende mogelijkheden zijn om de verschillende aspecten van professionaliteit te leren en te beoordelen. Veel wordt er al gedaan, maar het hier geboden referentiekader maakt duidelijk binnen welke context nog winst te behalen valt. De inspanningen van de opleiding moeten gericht zijn op de uitwerking en implementatie van de verschillende leeren toetssituaties naar de werkvloer. Cursorisch onderwijs is aanvullend en kan verdieping geven op datgene wat in de praktijk gebeurt. Naast het propageren van professionaliteit op de werkvloer dient specifieke aandacht besteed te worden aan signalering en remediering van onprofessioneel gedrag, aangezien dit een directe relatie heeft met patiëntveiligheid. ${ }^{31-32}$

\section{Conclusies}

De kenmerken van een professie en professional, en daarmee van het begrip professionaliteit, dienen altijd geplaatst te worden binnen de context, de tijd en de cultuur. De veranderingen van taken van de professional hebben alles te maken met een afnemende autonomie en een toenemende cultuur van verantwoording afleggen. Het begrip professionaliteit als een van de CanMEDS competenties wordt inzichtelijker indien professionaliteit alle activiteiten van het beroep omvat waarbij, afhankelijk van de rol, bepaalde aspecten van professionaliteit in meer of mindere mate naar voren komen. In de vervolgopleiding geldt dat professionaliteit binnen een team, organisatie en maatschappij nieuwe elementen zijn. Professionaliteit in de individuele arts-patiëntrelatie wordt voor een groot deel al gevormd in de basisopleiding. De groei van de professional in de vervolgopleiding zal met name op de werkvloer moeten gebeuren. Hiertoe bestaan legio mogelijkheden.

Uit de nieuwe opleidingsplannen van de vervolgopleidingen blijkt dat de groei als professional veel aandacht krijgt. Dat zou erop kunnen wijzen dat dit aspect van de opleiding voldoende ingebed is. Toch blijven er nog vele uitdagingen op dit gebied. Het onderwijs, gericht op het functioneren als professional, wordt nog onvoldoende geëxpliciteerd wanneer het gaat om doelen, methoden en effectiviteit. Studies die bruikbare indicatoren aangeven voor onprofessioneel handelen en die de daaruit voortvloeiende therapeutische mogelijkheden beschrijven zijn ook bijzonder schaars ${ }^{33-35}$ en behoeven nog veel aandacht. Hier ligt nog een taak voor de komende jaren. 
Tabel 1. Mogelijkheden met betrekking tot onderwijs in professionaliteit.

De rol van de professional binnen de .......

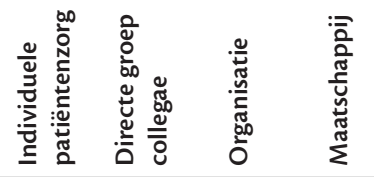

Leren van de professional door

Onderwijs in context

Stafleden

Mentoren als rolmodel

Supervisie krijgen

Supervisie geven onder begeleiding

Deelnemen Intervisie

Casuïstiek over handelen professionals / vignetten / dilemma's

(bv Medisch Contact)

Bespreken klachten patiënten / MIP meldingen

Continue feedback op gedragsmatig functioneren

Reflection in - en on action

Feedback op / nabespreking incidenten / klachten patiënt

Feedback op / nabespreking incidenten / klachten collegae

Oefenen / trainen kritische beroepssituaties (onder tijdsdruk)

Participatie in interdisciplinaire teams / projectgroepen

Journal club / conferentiebijdrage

Bespreken portfolio

Onderwijs buiten context zoals:

cursorisch onderwijs / nascholing / conferenties / workshops mbt

Werken in teams

Samenwerken

(simulatie) Teamtrainingen

Professionaliteit

Medische ethiek

Juridische aspecten van medisch handelen

Management (time, stress)

Leiderschap

Organisatie

Leren reflecteren

Gezondheidszorg in derde wereld

Aspecten gezondheid en maatschappij

Culturele diversiteit in de gezondheidszorg

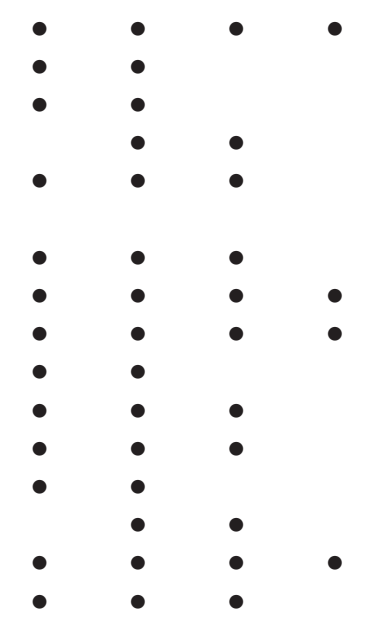


Tabel 2. Mogelijkheden met betrekking tot toetsing van professionaliteit.

De rol van de professional binnen de ......

Toetsing professional door

Selectie voor aanvang specialisatie

Toetsing in context

Registratie punctualiteit, aanwezigheid, houden aan deadlines

Zelfevaluatie verslag nav incident / klacht

Statusonderzoek

Bespreken portfolio

Toetsing kritische beroepssituaties (onder tijdsdruk)

Feedback patiënten / collegae (360 graden feedback)

Nabespreken casuïstiek / klachten / MIP meldingen

Casuïstiek bespreken over handelen professionals

Onderwijs geven / presenteren

Nabespreking teamopdrachten

Toetsing buiten context

(co) Auteurschap

Toetsing binnen de nascholing / cursorisch onderwijs

Toetsen patiënt tevredenheid

Toetsen leerklimaat

Toetsen werkklimaat

Toetsing aan de hand van vignetten

Gebruik checklisten / beoordelingslijsten gericht op (aspecten van)

professionaliteit

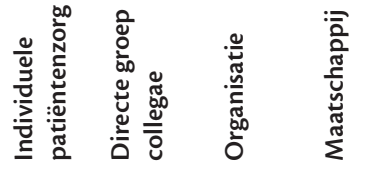

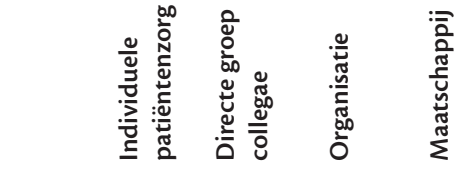

\section{-}
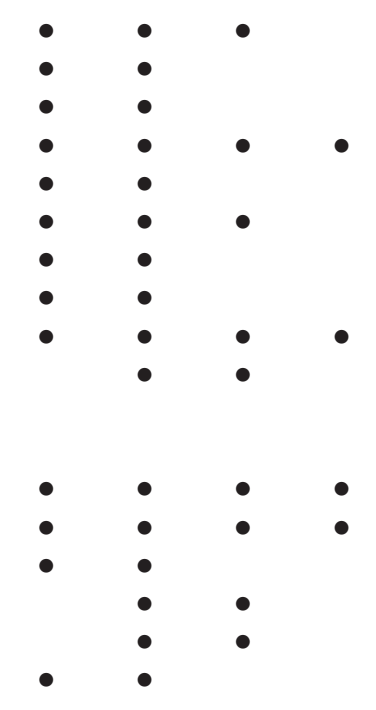

\section{Literatuur}

1. Erde EL. Professionalism's facets: ambiguity, ambivalence, and nostalgia. J Med Phil 2008;33: 6-26.

2. Elman NS, Robiner WN, Illfelder-Kaye J. Professional Development: Training for professionalism as a foundation for competent practice in psychology. Profesional Psychology 2005;36 (4):367-75.

3. Middelhurst R, Kennie T. Leading Professionals: Towards new concepts of professionalism. In: Broadbent J. Dietrich, M Roberts J (eds). The End of the Professions? The restructuring of professional work. London: Routledge; 1977:50-68.

4. Freidson E. The changing nature of professional control. Ann Rev Sociol 1984;10:1-20.

5. Sciully D. Professionals before professionalism. Ach European Sociology 2007;1:121-47.
6. Lawson WD Professionalism: the golden years. Journal of professional issues in engineering education and practice 2004;130 (jan):26-36.

7. Kalinka Van De Camp, Myrra JFJ Vernooij-Dassen, Richard PTM Grol. How to Conceptualize Professionalism: A Qualitative Study. Med Teach 2004;26(8):696-702.

8. Evetts J. The Sociological Analysis of Professionalism: Occupational Change in the Modern World. International Sociology 2003;18(2):395415.

9. Cruess SR, Johnston S, Cruess RL. "Profession": A working Definition for Medical Educators. Teach Learn Med 2004;16(1)74-76.

10. Working Party of the Royal College of Physicians, Doctors in society, medical professionalism in a 
changing world. Clinical Medicine 2005;5 (nr 6): suppl no 1: S17.

11. Amstrong D, Galloway D, Tomlinson S. The assessment of special educational needs and the proletarisation of professionals. British Journal of Sociology 1993:14 (4);399-408

12. Okkes IM \& Lamberts H (red). Onderhandelen in de spreekkamer. Posttraditionele geneeskunde en tandheelkunde. Bussum: Coutinho; 2000.

13. Hoogervorst. 'Autonomie arts niet van deze tijd'. Med Contact dec 2005; 49:1961.

14. Crul BVM. Hoofdredactioneel: Teamwork. Med Contact juni 2006; 22:899.

15. Stark C. To Kill and Kill Again - Dr Shipman. BMJ 2005;330:544.

16. Vesseur J. Een tekortschietend zorgproces, een onderzoek naar de kwaliteit en veiligheid van de cardiochirurgische zorgketen voor volwassenen in het UMC St Radbout te Nijmegen. Rapport externe onderzoekscie, april 2006.

17. Treasure T. Lessons from the Bristol Case. BMJ 1998;316:1685-86.

18. Orde, een veld in beweging. Med Contact juli 2004;28-29:1164.

19. Amerikaanse artsen ruziën over kwaliteitsindicatoren. Med Contact maart 2006;10:390.

20. Romano PS. Improving the Quality of Hospital Care in America. N Eng J Med 2005;353(3):302304.

21. KNMG Nieuwe wetgeving patientenrechten. Med Contact april 2008;17:740.

22. KNMG Versterking patientenrechten. Med Contact 2008; 24:1056-1057.

23. Rosenberg W, Donald A. Evidence based medicine, an approach to clinical problem solving. BMJ 1995; 310:1122-26.

24. Holtman M. A theoretical sketch of medical professionalism as a normative complex. Adv In Health Sci Educ 2008: 13: 233-45.

25. Broadbent J, Dietrich M, Roberts J (eds). The End of the Professions? The restructuring of professional work. In: Broadbent J. Dietrich M., Roberts J (eds). The End of the Professions? The restructuring of professional work. London: Routledge; 1977; 1-13.

26. Eve R, Hodgkin P. Professionalism and Medicine. In: Broadbent J, Dietrich M, Roberts J (eds). The End of the Professions? The restructuring of professional work. London: Routlegde; 1977;69-85.

27. Radtke RR. Role morality in the accounting profession. How do we compare to physicians and attorneys. Journal of Business Ethics 2008;79:279297.

28. Frank JR. (ED). The CanMEDS 2005 physician competency framework. Better Standards. Better Physicians. Better Care. Ottawa: The Royal College of Physicians and Surgeons of Canada; 2005.
29. KNMG Manifest, Medische Professionaliteit. Utrecht: april 2007.

30. Lee AG, Beaver HA, Boldt HC, Olson R, Oetting TA, Abramoff M, Carter K. Teaching and assessing professionalism in ophthalmology residency training programs. Survey of Ophthalmology 82; 3;300-314.

31. Papadakis M, Arnold G, Blank L, Holmboe E, Lipner R. Performance during Internal Medicine Residency Training and Subsequent Disciplinary Action by State Licensing Boards. Annals of Internal Medicine 2008; 148 (11): 869-76.

32. Hickson GB, Pichert JW, Webb LE, Gabbe SG. A complementary approach to promoting professionalism: Identifying, measuring, and addressing unprofessional behaviors. Acad Med 2007; 82:1040-48.

33. Stern DT, Frohna AZ, Gruppen LD. The prediction of professional behaviour. Med Educ 2005; 39:75-82

34. Maxine A. Papadakis M.D, Arianne Teherani, Ph.D., Mary A. Banach, Ph.D., M.P.H., Timothy R. Knettler, M.B.A., Susan L. Rattner, M.D., David T. Stern, M.D., Ph.D., J. Jon Veloski, M.S., and Carol S. Hodgson, Ph.D. Disciplinary Action by Medical Boards and Prior Behavior in Medical School. N Engl J Med 2005;353(25):2673-2682.

35. Roback HB, Strassberg D, Ianelli RJ, Finlayson AJR, Blanco M, Neufeld R. Problematic Physicians: a comparison of personality profiles by offence type. Can J Psychiatry 2007; 52:315-322.

De auteurs:

Dr. S.J. van Luijk, arts/onderwijskundige, VU medisch centrum, Instituut voor Onderwijs en Opleiden, Amsterdam.

W.N.K.A. van Mook, MD, internist-intensivist, Departments of Intensive Care and Internal Medicine, Maastricht University Medical Center, Maastricht.

Drs. W.P.J. van Oosterhout, arts-onderzoeker Neurologie, Leids Universitair Medisch Centrum, Leiden.

\section{Correspondentieadres:}

Dr. S.J. van Luijk, Instituut voor Onderwijs en Opleiden, VU Medisch centrum, Van der Boechorststraat 7 (Kamer D-239), 1081 BT Amsterdam. Tel. 020-4445869; e-mail:sj.vanluijk@vumc.nl

Belangenconflict: geen gemeld

Financiële ondersteuning: geen gemeld 


\section{Summary}

This article looks at the different meaning of the term 'professional' and 'professionalism' in different contexts. Within medical schools the term 'professional behaviour' is used with reference to the behaviour students are expected to show when performing in a team, during group work and on the wards.

Within the context of postgraduate specialist training 'professional' and 'professionalism' refer to one of the competencies of the CanMEDS model which has been adopted by all the specialities in the Netherlands. This article compares the CanMEDS definition of professional and professionalism with definitions used in other disciplines. From this comparison it appears that other disciplines define professionalism more broadly as comprising all the competencies of the CanMEDS model. Based on a review of the literature, the authors arrive at the following defintion of a professional.

A professional is a person who has acquired specialised knowledge and skills through intensive training, study and experience and is able to apply these in accordance with the rules and regulations of the profession, organization or government, which are accountable for all the actions of professionals to the different parties concerned. This is determined by the culture, the context and the time in which the professional is active. This implies that 'professionalism' is a dynamic concept! The definition of a professional is thus dependent on context, time and culture.

In different contexts different aspects of professionalism are manifested. The authors distinguish four roles of professionals; the professional working as an individual, the professional working in a team, the professional working within an organization and the professional as a member of the society. Various roles can be appropriate in a certain context. For all the different roles different teaching and assessment methods can be applied. (Luijk SJ van, Mook WNKA van, Oosterhout WPJ van. Teaching and assessing professionalism. Dutch Journal of Medical Education 2009;28(3):107-118.) 